\title{
Acute Abdomen from Chylous Peritonitis: A Surgical Diagnosis
}

\section{Case Report and Literature Review}

\author{
N. Vettoretto M. Odeh M. Romessis G. Pettinato L. Taglietti M. Giovanetti \\ General and Vascular Surgery, M. Mellini Hospital, Chiari, Italy
}

\section{Key Words}

Chylous peritonitis $\cdot$ Laparoscopy

\begin{abstract}
Acute accumulation of chyle in the peritoneal cavity is a rare event (less than 100 cases are described in the literature) and is to be distinguished from chylous ascites, which is characteristically chronic. It is frequently idiopathic, and diagnosis is usually made at laparotomy, whenever signs of acute peritonitis impose it. Peritoneal toilette and drainage are the only treatment required, and the prognosis is excellent. We describe the case of a 69-year-old man who underwent emergency surgery for acute peritonitis. Approximately 0.5 liters of chyle were found free in the peritoneal cavity at laparoscopic exploration, without any important underlying pathological condition apart from a blood vessel congestion in the bowel resembling angiomatosis. Laparotomic conversion, peritoneal toilette and drainage, with postoperative low-fat diet, were the pursued treatments. Two years after discharge, chemistry and clinics are normal, without evidence of associated disease or recurrence.
\end{abstract}

Copyright $\odot 2008$ S. Karger AG, Basel

\section{Introduction}

Chylous extravasation into the peritoneal cavity is an uncommon event; a sudden outpour of chyle might manifest itself as acute peritonitis. This unusual phenomenon may be secondary to various disease processes in which a correct diagnosis is seldom made preoperatively. A small number of cases of acute chylous peritonitis have been described in the literature. We have discussed the clinical features and management of this case, in comparison to other common surgical abdominal emergencies and to previous case reports.

\section{Case Report}

A 69-year-old man was referred to the emergency room, because of generalized and continuous abdominal pain. There was nothing relevant in the past medical history except for appendectomy; no trauma was referred nor anything particular in life habits or familiar illnesses. Important abdominal tenderness and diffuse guarding suggested acute peritonitis.

Blood chemistry showed the following values: leukocyte count $12.53 \times 10^{3} / \mu \mathrm{l}$; hemoglobin $17.4 \mathrm{~g} / \mathrm{dl}$; platelets $223 \times 10^{3} / \mu \mathrm{l}$; neutrophils $73.8 \%$; lymphocytes $19 \%$; $\mathrm{Na}^{+} 143 \mathrm{mmol} / \mathrm{l} ; \mathrm{K}^{+} 4.52$ $\mathrm{mmol} / \mathrm{l}$; urea $59 \mathrm{mg} / \mathrm{dl}$; creatinine $0.86 \mathrm{mg} / \mathrm{dl}$; bilirubin $1.11 \mathrm{mg} /$ $\mathrm{dl}$; amylase $112 \mathrm{U} / \mathrm{l}$; aspartate aminotransferase $31 \mathrm{U} / \mathrm{l}$; alanine aminotransferase $25 \mathrm{U} / \mathrm{l}$. Urine examination showed microhematuria. Abdominal X-rays evidenced paralytic ileus and a subdia-

Nereo Vettoretto

Chirurgia Generale e Vascolare, Az. Osp. M. Mellini

Viale Mazzini 4

IT-25032 Chiari, BS (Italy)

Tel. +39030710 2799, Fax +39030710 2468, E-Mail nereovet@hotmail.com 


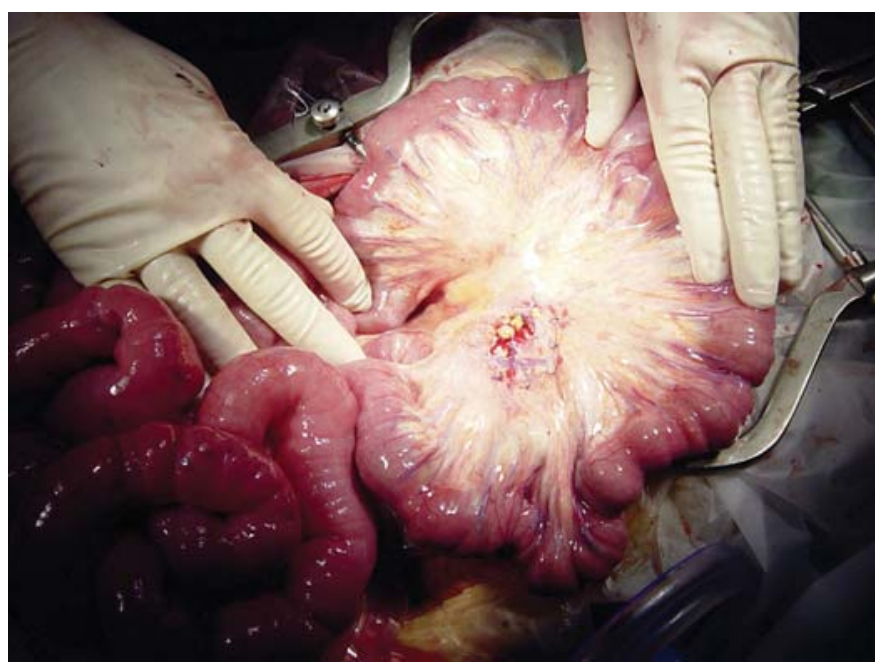

Fig. 1. Chylous extravasation and thickening of the mesentery, with biopsy specimen taken.

phragmatic gas lucency interpreted as either stomach gas or free air from a perforated viscus. The increasing tenderness (badly controlled by analgesic therapy) associated with a diffuse guarding (that pointed to a suspected acute perforation of a hollow viscus) called for an immediate laparoscopy instead of a preoperative CT scan.

At exploration there was neither evidence of stomach, duodenum or colon perforation nor of the other most common surgical causes of peritonitis (cholecystitis, appendicitis, intestinal ischemia or diverticulitis), but alas a large amount of milky fluid filled the peritoneal cavity, associated with distension of the small bowel and angioma-like cherry spots affecting the transverse colon and the small intestine; after conversion to laparotomy, samples of the chylous liquid were taken for bacteriological, biochemical and cytological examination. A biopsy of the root of the mesentery was also performed for its thickened appearance, presenting palpable nodes and its peritoneal surface covered by fine granulations (fig. 1). On gross examination, no abnormalities could be detected in any of the solid or hollow abdominal viscera with the exception of the described small-vessel hypertrophy forming little angiomas on the mesenteric side of the bowel (fig. 2). There were no dilated lymphatics, and no source of leakage was found. A thorough peritoneal wash with warm saline was performed, and drains were positioned. Drainage of about $100 \mathrm{ml}$ of chyle was observed only in the first $24 \mathrm{~h}$.

Biochemical analysis of the peritoneal fluid revealed elevated values of lipases $(622 \mathrm{U} / \mathrm{l})$, amylases $(325 \mathrm{U} / \mathrm{l})$ and triglycerides $(312 \mathrm{mg} / \mathrm{dl})$. Triglycerides and proteins in plasma were within the normal range just like the serum amylase level. The fluid was bacteriologically sterile. Histological examination of the mesentery specimen evidenced nonspecific fibrocalcific nodes.

The postoperative period was uneventful, drains were removed on the 7th postoperative day (in the presence of a clear aspect of the peritoneal fluid after a few days with total parenteral nutrition and subsequent return to oral intake), and the pa-

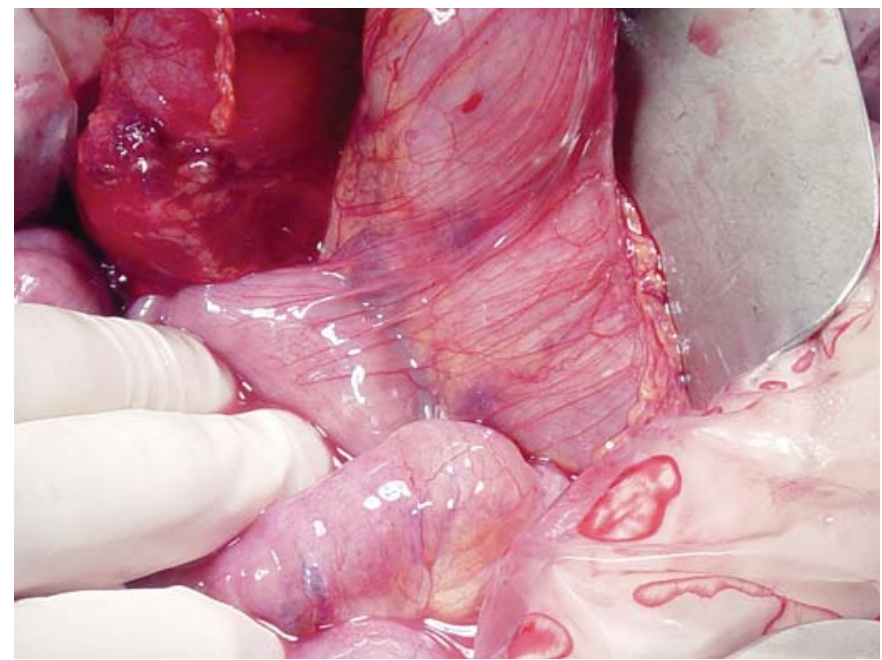

Fig. 2. Hypertrophied jejunal vessels resembling angiomatosis.

tient was discharged on the 8th postoperative day with a low-fat diet prolonged for 2 weeks. Follow-up was achieved with oncological markers, chest X-ray and CT scan of the abdomen (at 3, 6, 12 and 24 months). No abnormalities were diagnosed, neither abdominal/thoracic masses nor lymphatic dysplasia. He never complained of diarrhea or any other symptom of malabsorption, and fecal examination (lipid-protein digestion, parasites and fecal $\alpha_{1^{-}}$ antitrypsin) was normal. After 2 years, no malignancy or any recurrence of chylous ascites has been evidenced.

\section{Discussion}

Chylous ascites is characterized by lymphatic fluid leaking into the abdominal cavity and has a prevalence of about 1/20,000 admissions to hospital care [1]; when the output of chyle takes place rapidly, we can observe an acute peritoneal reaction called acute chylous peritonitis. The gut lymphatics carry converted long-chain triglycerides from the intestine to the vascular system via the thoracic collecting duct. The inflow through this duct may vary from 50 to $200 \mathrm{ml} / \mathrm{h}$; the flow markedly increases with the ingestion of fatty meals [2]. Although sometimes caused by trauma (the impact does not need to be violent to produce chylous leakage), abdominal or aortic surgery, tuberculosis, liver cirrhosis or different peritoneal infections, it is frequently found in the presence of malignancies. Krizek and Davis [3] classify patients with chylous peritonitis into obstructive, traumatic, idiopathic types and those associated with mesenteric cysts. In the ob- 
structive type, an increased pressure within the thoracic duct or the liver results in lymph stasis, edema and consequent rupture of small lymphatic vessels, leading to chylous effusion. Congenital causes are more common in infants, while inflammatory and neoplastic causes are more common in adults [4]. Nephritis, filariasis, bilharziasis and thoracic duct obstruction by aortic aneurysm are other conditions associated with chylous effusions [5]. Some authors suspect that chyle extravasation can occur after heavy fatty meals with consequent overload of the lymphatic channels [6]. In the present case no malignancies were evidenced, or any trauma reported, and the patient negated fatty meals; instead, a mild form of congenital malformation involving smaller vessels (including lymphatics) was suspected according to the association with small multiple angiomas on the mesenteric side of the bowel. A histological specimen of the mesentery though showed no evidence of lymph node or vessel abnormalities. An undetermined etiology, investigated either postoperatively or postmortem, still accounts for the majority of the cases.

Free chyle is relatively nonirritating to the serosal surface, but pain may result from the stretching of the retroperitoneum and the mesenteric serosa [6]. In the present case, an acute abdominal tenderness and guarding, thus mimicking bowel perforation, was noticeable since the onset of symptoms, and pain did not regress with common analgesics. There was no correlation between pain and retroperitoneal bulging, for the latter was minimal; instead, there was a lot of free chyle in the cavity: this does make us suppose that chyle could play a part in the pain evoked by contact with peritoneal serosa, especially in the case of sudden outpour.

Abdominal surgery is another common cause of chylous ascites, for it has been frequently associated with aortic substitution for aneurysm, with retroperitoneal lymph node dissection [7] or with sigmoid volvulus.

The first case of acute chylous peritonitis was described by Renner [8] in 1910; since then less than 100 cases have been reported in the literature, and thus very little information is available regarding its etiology, diagnosis and treatment. The review published by Thompson et al. [9] reported 56 cases in the English literature up to 1981; a Medline research in the world literature (using Pubmed), considering only adult cases of peritonitis due to acute chylous extravasation, evidenced 15 more cases reported in the literature, bringing the total to 71 . Some of these cases simulated acute appendicitis, pancreatitis or ovarian torsion, some others have been associated with heavy meal eating, nephritis, appendicitis or pancreatitis.
Most of them were ascribed to an idiopathic etiology [1024].

Chylous effusion must be differentiated from pus, pseudochyle and ascites [25]. Chyle is distinguished by its milky appearance similar to peripheral lymph. It is normally odorless and only occasionally smells like digested food. The white cell count averages $5,000 / \mathrm{ml}$, and it is essentially constituted by lymphocytes. It shows bacteriostatic properties, is sterile in culture and resists putrefaction. The main in vitro characteristics are separation into a creamy layer on standing, alkaline chemical properties, specific gravity greater than 1.012 , total protein value of $3 \%$, staining of fat globules with Sudan red stain, a fat content of $0.4-4 \%$ and total solids $>4 \%$ [26]. The triglyceride level is an important diagnostic tool, and concentration in chylous ascites is typically $2-8$ times that of plasma [27]. True chylous ascites must be distinguished from 'chyliform' and 'pseudochylous' effusions, in which the turbid appearance is due to cellular degeneration from bacterial peritonitis or neoplasm. Pseudochyle is an opalescent chyle-like fluid aspirated from patients with widespread peritoneal seeding of a malignant neoplasm (e.g. pseudomyxoma peritonei). Peritoneal tuberculosis can easily be differentiated by laboratory tests [28]. Moreover, the triglyceride concentration is low in these cases. Other diagnostic tests such as computed tomography, lymphangiography, lymphoscintigraphy and laparotomy give the highest yield of diagnostic information [4], but they are usually reserved to nonemergency situations as in chylous ascites. A CT scan can demonstrate fluid collection with a density index similar to that of water (attenuation coefficients ranging from 1 to 4 Hounsfield units) [29]; it can also show enlarged lymph nodes (in tuberculosis or hematological malignancies), other abdominal tumors or inflammation of the mesentery (as in sclerosing mesenteritis) [30]. In this case the emergency setting did not permit a CT scan, which would have allowed the exclusion of the free air suspicion given by plain films, but would probably not have been diagnostic of the etiology (the postoperative CT scan done for follow-up purposes was normal after 3 months). Interstitial MRI lymphography has proven, in some recent studies [31], to be reliable for the detection of lymphatic dysplasia (especially in lower limb lymphedema) and could have been useful in the postoperative assessment of this etiology. The examination though has not proven its efficacy outside experimental studies or chronically symptomatic patients (i.e. refractory chylous ascites). Moreover there is no indication for the surgical correction of abdominal lym- 
phatics in asymptomatic subjects, even in the case of MRI-established lymphatic abnormalities [32].

The management of chylous peritonitis depends on its underlying etiology. In patients with symptoms of an acute abdominal process, immediate exploration is mandatory. The source of chylous extravasation can be corrected by ligation of leaking lymphatics or removal of offending lesions. Nonsurgical therapy includes total parenteral nutrition, used to achieve complete bowel rest, thus decreasing the rate of chyle formation. Fasting and total parenteral nutrition might allow resolution of the chylous ascites by inhibiting lymph fluid excretion through specific receptors found in the normal intestinal wall [33]. Post-intensive-care diet has the goal to decrease the rate of chyle formation by providing high-protein and low-fat food.

We have presented an unusual case of spontaneous chylous-ascites-related peritonitis in a young adult man. This case points out the role of laparoscopy in the early diagnosis of acute abdomen, regardless of the suspected etiology [34]. In this rare condition, the authors excluded the most common causes of peritonitis and thus preferred conversion to laparotomy in order to securely explore the root of the mesentery and the retroperitoneum, frequent pitfalls in laparoscopic diagnosis. Almost all the cases reported in the literature required laparotomy for diagnosis, and in most of them a complete lavage of the peritoneal cavity and drainage were sufficient to achieve resolution of the acute symptoms. Only 2 cases have not undergone surgery as chylous effusion was diagnosed by explorative puncture: both patients were affected by acute pancreatitis, and for this reason a nonoperative choice was preferred, resolving the chylous ascites by prolonged fasting and total parenteral nutrition $[3,9]$. The prognosis in surgically treated emergencies seems to be excellent, since all the reported cases recovered completely with no recurrence. In this patient, the follow-up after 2 years did not evidence any recurrence.

\section{References}

1 Press PW, Press NO, Kaufman SD: Evaluation and management of chylous ascites. Ann Intern Med 1982;96:358-365.

-2 Madding GF, McLaughlin RF, McLaughlin RF Jr: Acute chylous peritonitis. Ann Surg 1958;147:419-422.

-3 Krizek TJ, Davis JH: Acute chylous peritonitis. Arch Surg 1965;91:253-262.

4 Browse NL, Wilson NM, Russo F, al-Hassan $\mathrm{H}$, Allen DR: Aetiology and treatment of chylous ascites. Br J Surg 1992;79:1145-1150.

5 Vasko JS, Tapper RI: The surgical significance of chylous ascites. Arch Surg 1967;95: 355-368.

6 Weichert RF, Jamieson CW: Acute chylous peritonitis: a case report: Br J Surg 1970;57: 230-232.

7 Combe J, Buniet JM, Bernard Y, Camelot G: Chylothorax and chyloascites following surgery of an inflammatory aneurysm: case report with review of the literature. J Mal Vasc 1992;17:151-156.

8 Renner A: Chylus als Bruchwasser beim eingeklemmten Bruch. Beitr Klin Chir 1910; 70:695-698.

$\checkmark 9$ Thompson PA, Halpern NB, Aldrete JS: Acute chylous peritonitis. J Clin Gastroenterol 1981;3(suppl 1):51-55.

10 Bhattacharya P: Acute chylous peritonitis. Indian J Surg 2002;64:525-526.

- 11 Fang FC, Hsu SD, Chen CW, Chen TW: Spontaneous chylous peritonitis mimicking acute appendicitis: a case report and review of the literature. World J Gastroenterol 2006; 12:154-156

12 Fazili MF, Khawaja FI: Acute chylous peritonitis simulating acute appendicitis: a case re- port and review of the literature. Ann Saudi Med 1999;19:236-238.

13 Michel P, Pagliano G: Acute chyloperitone um. J Chir (Paris) 1992;129:544-549.

14 Lamblin A, Mulliez E, Lemaitre L, Pattou F, Proye C: Acute peritonitis: a rare presentation of chylous ascites. Ann Chir 2003;128: 49-52.

15 Shalev M, Witz M, Erez I, Dinbar A: Chylous ascites imitating acute appendicitis. Harefuah 1991;121:238-239.

16 Spasiuk MI, Spasiuk MD, Spasiuk NI: Chylous peritonitis associated with acute phlegmonous appendicitis. Klin Khir 1989;4:66.

17 Iuldashev AA, Iuldashev AA: Chylous peritonitis associated with right side perinephritis. Khirurgiia (Mosk) 1990;12:144-145.

18 Krivov I: Chylous peritonitis of alimentary etiology. Vestn Khir Im I I Grek 1984;133: 69-70.

19 Chichetka AA, Biriukova LN: Chylous peritonitis simulating acute appendicitis. Vestn Khir Im I I Grek 1991;146:44.

20 Kotel'nikov AS, Pul'nikov PD, Zuev LN, Tabakov SG: Chylous peritonitis. Klin Khir 1988;4:72-73.

21 Broll A, Cygan J, Kaminski A: Recurrent acute chylous peritonitis. Wiad Lek 1992;45: 381-383.

-22 Hares MM: Acute chylous peritonitis. J R Coll Surg Edinb 1982;27:116.

23 Currier H: Chylous ascites: an unexpected complication that resembles peritonitis. ANNA J 1995;22:157-159.

24 Kang CM, Kim S, Kim BW, Kim KS, Choi JS, Lee WJ, Kim BR: Acute chylous peritonitis mimicking ovarian torsion in a patient with advanced gastric carcinoma. J Korean Med Sci 2007;22(suppl):164-166.

25 Cardenas A, Chopra S: Chylous ascites. Am J Gastroenterol 2002;97:1896-1900.

26 Dreznik Z, Dinbar A, Wolfstein I, Tulcinsky DB: Acute chylous peritonitis: a case report with a review of the literature. Isr J Med Sci 1973;9:89-91.

27 Ward PC: Interpretation of ascitic fluid data. Postgrad Med 1982;71:171-173, 176-178.

28 Jhittay PS, Wolverson RL, Wilson AO: Acute chylous peritonitis with associated intestinal tuberculosis. J Pediatr Surg 1986;21:75-76.

29 Hibbeln JF, Wehmueller MD, Wilbur AC: Chylous ascites: CT and ultrasound appearance. Abdom Imaging 1995;20:138-140.

30 Horton KM, Lawler LP, Fishman EK: CT findings in sclerosing mesenteritis (panniculitis): spectrum of disease. Radiographics 2003;23:1561-1567.

>31 Lohrmann C, Foeldi E, Speck O, Langer M: High-resolution MR lymphangiography in patients with primary and secondary lymphedema. AJR Am J Roentgenol 2006;187:556561.

>32 Shen WB, Sun YG, Xia S, Wu GF, Geng WD, Sun YX, Chang K: The diagnosis and therapy of chylous ascites. Zhonghua Wai Ke Za Zhi 2005;43:25-28.

33 Ohri SK, Patel T, Desa LA, Spencer J: The management of postoperative chylous ascites: a case report and literature review. J Clin Gastroenterol 1990;12:693-697.

34 Agresta F, Ciardo LF, Mazzarolo G, Michelet I, Orsi G, Trentin G, Bedin N: Peritonitis: laparoscopic approach. World J Emerg Surg 2006;1:9. 